\title{
Measurement of Right Ventricular End-systolic and End-diastolic Volumes by the Thermodilution Technique
}

\author{
RAPHAEL BALCON` AND SAMUEL ORAM \\ From the Cardiac Department, King's College Hospital, London S.E.5
}

At the present time there is no entirely satisfactory index of ventricular function. End-diastolic pressure is often used as it can be relatively easily measured and, with other factors, is related to the length of myocardial fibres at the end of diastole. Ventricular end-diastolic volume (EDV) is, however, a much closer approximation of fibre length, because, as Starling and Visscher (1927) have shown, it determines the force of subsequent ventricular contraction and the stroke volume (SV). Endsystolic volume (ESV) and the ratio ESV/EDV are also indicators of ventricular functional capacity. Early attempts to measure heart volumes were made using measurements from $x$-rays (Rohrer, 1916; Geigel, 1920; Kahlstorf, 1932). The advent of angiocardiography has provided another line of approach (Rushmer and Thal, 1951; Dodge et al., 1960; Arvidsson, 1961; Miller and Swan, 1964). Indicator dilution curves may also be used to measure ventricular volumes.

The curves used to measure cardiac output have a smooth downslope produced by the gradual removal of indicator from the heart. In fact, the indicator is expelled from the ventricle in small amounts with each systole, and the changes in concentration at the sensing site take place in a stepwise fashion. This stepwise washout is modified by the relatively slow time response of the sensing device and the conducting system carrying blood to it from the sensing site. Fig. 1 shows a diagrammatic representation of a washout curve with a stepwise decrease in indicator concentration. It also shows the way in which the ratio ESV/EDV can be calculated from it.

Received January 23, 1968.

^ In receipt of a British Heart Foundation grant. Present address: National Heart Hospital, London W.1.
Applying this basic principle, Bing, Heimbecker, and Falholt (1951) attempted to analyse the washout phase of Evans blue dilution curves to obtain residual ventricular volume. The calculations were hampered by the modification of the curve due to the sensing apparatus. They constructed models

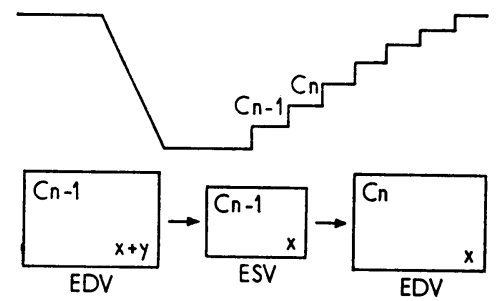

QUANTITY OF INDICATOR = CONCENTRATION OF INDICATOR $X$ VENTRICULAR VOLUME

$x=C_{n-1}(E S V)=C_{n}(E D V)$

Cross multiplying:

$E D V-E S V=S V$

$$
\frac{E S V}{E D V}=\frac{C_{n}}{\epsilon_{n-1}}
$$

Dividing by EDV :

$$
1-\frac{E S V}{E D V}=\frac{S V}{E D V}
$$

Cross multiplying :

$$
E D V=\frac{S V}{1-\frac{E S V}{E D V}}
$$

FIG. 1.-A diagrammatic representation of an indicator dilution curve is shown above. Beneath the curve are shown squares representing the ventricle in end-diastole (EDV) and end-systole (ESV). $x$ and $x+y$ represent quantities of indicator. $\mathrm{Cn}-1$ and $\mathrm{Cn}$ represent successive concentrations of indicator. EDV, end-diastolic volume; ESV, end-systolic volume; and SV, stroke volume. The mathematical steps to derive the formula EDV $=\frac{S V}{1-\frac{E S V}{\overline{E D V}}}$ are shown. 
in an effort to find what corrections should be applied to the formula to obtain useful results.

Holt (1956), working with dogs, attempted to overcome these problems in two ways. First, he used rapid intermittent sampling of Evans blue and then constructed a stepwise curve. He then used saline as the indicator and measured changes in electrical conductivity produced by it. This was the first system with a sufficiently rapid response to give stepwise washout curves.

Rapaport, Weigand, and Bristow (1962) used cooled saline as the indicator and a thermistor bead mounted at the tip of a cardiac catheter to sense the changes in temperature produced. This system responded rapidly, and since the sensing device could be placed just distal to the ventricle it overcame distortion from a long system conducting blood to a sensing device outside the body. The first work was done in dogs, but later they used the technique in patients (Bristow et al., 1964; Rapaport et al., 1965). Other workers have since used this method to measure ventricular volumes in man in various conditions (Elliott, Lane, and Gorlin, 1964; Rolett, Sherman, and Gorlin, 1964; Lewis, Bristow, and Griswold, 1967). It is known as the thermodilution technique, and is the method used to measure right ventricular volumes in a group of patients described here.

\section{SUBJECTS AND METHODS}

The patients were all undergoing routine cardiac catheterization in the fasting state after premedication with 100 to $200 \mathrm{mg}$. of quinalbarbitone. Pressures were recorded with an Elema-Schonander strain gauge and mingograph recorder. The zero level was at the sternal angle. Cardiac output was measured by the Fick principle, oxygen saturations were estimated on a Kipp and Zonen haemoreflector and oxygen content of expired air on a paramagnetic oxygen meter. A thermistor catheter made in the Physics Department of King's College Hospital was used in the early cases, and in the later ones a USCl${ }^{\star}$ No. 7 double lumen thermistor catheter, with the thermistor sealing off the distal lumen. Both catheters had similar characteristics, with a rapid time response (time constant less than $0.2 \mathrm{sec}$.) and a linear response over the temperature range at which they were used (Fig. 2). The thermistor catheter was positioned in the pulmonary artery. Approximately $5 \mathrm{ml}$. ice cold saline were injected into the right ventricle just beyond the tricuspid valve, through the proximal lumen of the double lumen catheter or through a second catheter when the King's College Hospital catheter was used. The thermistor catheter was placed in one arm of a Wheatstone bridge, the output of which was coupled to a Sanborn carrier amplifier. Pressures were recorded and cardiac output measured, and immediately afterwards

* United States Catheter Inc. the thermodilution curves were recorded. Stroke volume was obtained by dividing cardiac output by heart rate.

The theoretical curve shown in Fig. 1 can now be used to represent a thermodilution curve.

The steps on the upstroke of the curve represent changes in resistance of the thermistor bead, which occur in a linear fashion and can be equated with the changes in concentration of saline seen as rewarming. It is assumed that indicator concentrations measured in the pulmonary artery represent the concentrations in the ventricle at the end of the previous diastole (Brecher and Hubay, 1955), and that the volumes do not change appreciably while the curve is recorded. Maximal mixing occurs four beats after peak cooling (Irisawa, Wilson, and Rushmer, 1960), and thus the first four beats after this have not been used in the calculations. At least three curves were analysed in each patient to obtain a mean value for ESV/EDV. From this ratio and stroke volume obtained from Fick cardiac outputs, absolute values for end-systolic and end-diastolic volumes were obtained as shown in Fig. 1.

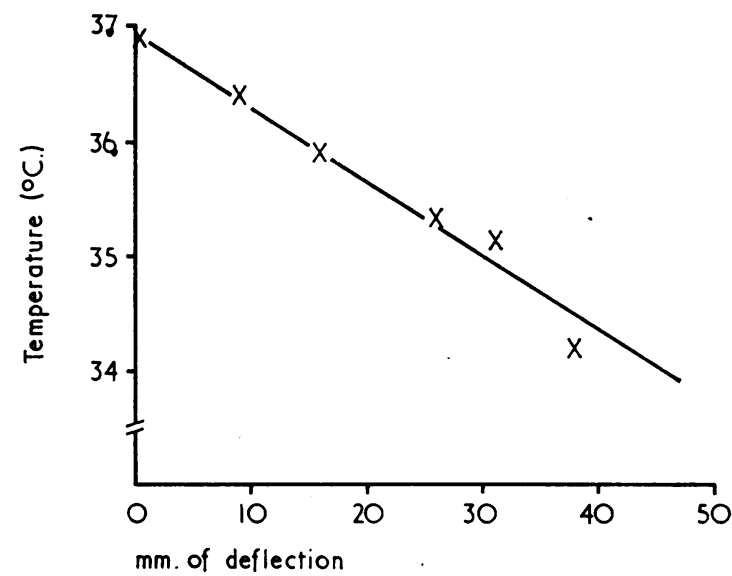

Fig. 2.-Recorder deflection is shown against changes in temperature. These points were obtained by plunging the thermistor catheter from air into still water.

Satisfactory thermodilution curves were obtained in 22 patients. Four of these had predominantly left ventricular disease, and are not considered further here. The remaining 18 patients have been divided into two groups. The first consisted of 6 patients who were symptom free and who can be considered to have "normal" hearts. Of these, 3 had pectus excavatus, 2, one of whom had right bundle-branch block, were investigated because of systolic murmurs which proved to be innocent, and there was one patient with hepatic cirrhosis in whom the hepatic wedge pressure was being measured. The second group consisted of 12 patients with mitral valve disease: 10 had dominant stenosis of varying severity and 2 had non-rheumatic mitral regurgitation. 
TABLE I

CLINICAL FEATURES AND RESULTS IN "NORMAL" GROUP

\begin{tabular}{|c|c|c|c|c|c|c|c|c|c|c|c|c|c|c|}
\hline Patient & $\begin{array}{l}\text { Age } \\
\text { (yr.) }\end{array}$ & Sex & Diagnosis & $\begin{array}{c}\text { Clinical } \\
\text { severity } \\
\text { (New } \\
\text { York } \\
\text { Heart } \\
\text { Assoc. } \\
\text { grades) }\end{array}$ & $\begin{array}{c}\text { Heart } \\
\text { rate } \\
\text { (beats } \\
\text { per } \\
\text { min.) }\end{array}$ & $\begin{array}{l}\text { Right } \\
\text { ventri- } \\
\text { cular } \\
\text { systolic } \\
\text { pressure } \\
\text { (mm. } \\
\text { Hg) }\end{array}$ & $\begin{array}{c}\text { Right } \\
\text { ventri- } \\
\text { cular } \\
\text { end- } \\
\text { diastolic } \\
\text { pressure } \\
\text { (mm. } \\
\mathbf{H g})\end{array}$ & $\begin{array}{l}\text { Cardiac } \\
\text { index } \\
\text { (ml./m. } .^{2} \\
\text { B.S.A.) }\end{array}$ & $\begin{array}{c}\text { Stroke } \\
\text { index } \\
\text { (ml./m. } .^{2} \\
\text { B.S.A.) }\end{array}$ & $\begin{array}{l}\text { End- } \\
\text { diastolic } \\
\text { volume } \\
\text { (ml./m. }{ }^{2} \\
\text { B.S.A.) }\end{array}$ & $\begin{array}{c}\text { End- } \\
\text { systolic } \\
\text { volume } \\
\text { (ml./m. } \\
\text { B.S.A.) }\end{array}$ & $\begin{array}{c}\text { Pul- } \\
\text { monary } \\
\text { capillary } \\
\text { venous } \\
\text { pressure } \\
\left(\begin{array}{c}\text { mm. } \\
\text { Hg) }\end{array}\right.\end{array}$ & $\frac{\text { ESV }}{\text { EDV }}$ & $\begin{array}{c}\text { Right } \\
\text { ventri- } \\
\text { cular } \\
\text { stroke } \\
\text { work } \\
\text { (g.m.// } \\
\text { stroke/ } \\
\text { m.2 } \\
\text { B.S.A.) }\end{array}$ \\
\hline J.A. & 19 & $\mathbf{F}$ & Pectus & 0 & 75 & 25 & 5 & $3 \cdot 1$ & 42 & 161 & 119 & $2 \cdot 5$ & 0.74 & $14 \cdot 3$ \\
\hline A.S. & 39 & $\mathbf{M}$ & $\begin{array}{l}\text { excavatus } \\
\text { Pectus }\end{array}$ & 0 & 63 & 25 & 5 & $2 \cdot 4$ & 38 & 110 & 71 & $8 \cdot 0$ & 0.65 & $12 \cdot 9$ \\
\hline J.F. & 23 & $M$ & $\begin{array}{l}\text { excavatus } \\
\text { Pectus }\end{array}$ & 0 & 68 & 17 & 3 & $2 \cdot 3$ & 34 & 130 & 96 & $7 \cdot 0$ & $0 \cdot 74$ & $7 \cdot 9$ \\
\hline P.A. & 18 & $\mathbf{F}$ & $\begin{array}{c}\text { excavatus } \\
\text { Innocent } \\
\text { systolic }\end{array}$ & 0 & 91 & 25 & 7 & $2 \cdot 8$ & 30 & 86 & 56 & 10.0 & 0.65 & $10 \cdot 2$ \\
\hline A.B. & 44 & $M$ & $\begin{array}{l}\text { murmur } \\
\text { Innocent } \\
\text { systolic } \\
\text { murmur, }\end{array}$ & 0 & 71 & 25 & 3 & $2 \cdot 3$ & 32 & 105 & 73 & $5 \cdot 0$ & $0 \cdot 70$ & 10.9 \\
\hline J.W. & 57 & $\mathbf{M}$ & $\begin{array}{c}\text { RBBB } \\
\text { Hepatic } \\
\text { cirrhosis }\end{array}$ & 0 & 79 & 30 & 5 & $3 \cdot 4$ & 43 & 103 & 60 & $5 \cdot 0$ & 0.58 & $17 \cdot 5$ \\
\hline
\end{tabular}

TABLE II

CLINICAL FEATURES AND RESULTS IN GROUP WITH MITRAL VALVE DISEASE

\begin{tabular}{|c|c|c|c|c|c|c|c|c|c|c|c|c|c|c|}
\hline \multirow[t]{2}{*}{ Patient } & \multirow[t]{2}{*}{$\begin{array}{l}\text { Age } \\
\text { (yr.) }\end{array}$} & \multirow[t]{2}{*}{ Sex } & \multirow{2}{*}{$\begin{array}{c}\text { Clinical } \\
\text { severity } \\
\text { (New } \\
\text { York } \\
\text { Heart } \\
\text { Assoc. } \\
\text { grades) }\end{array}$} & \multirow[t]{2}{*}{$\begin{array}{c}\text { Heart } \\
\text { rate } \\
\text { (beats } \\
\text { per } \\
\text { min.) }\end{array}$} & \multirow{2}{*}{$\begin{array}{c}\text { Right } \\
\text { ventri- } \\
\text { cular } \\
\text { systolic } \\
\text { pressure } \\
\text { (mm. } \\
\text { Hg) }\end{array}$} & \multirow[t]{2}{*}{$\begin{array}{c}\text { Right } \\
\text { ventri- } \\
\text { cular } \\
\text { end- } \\
\text { diastolic } \\
\text { pressure } \\
\text { (mm. } \\
\text { Hg) }\end{array}$} & \multicolumn{2}{|c|}{$\begin{array}{l}\text { Pulmonary } \\
\text { capillary } \\
\text { venous } \\
\text { pressure } \\
\text { (mm. Hg) }\end{array}$} & \multirow[t]{2}{*}{$\begin{array}{l}\text { Cardiac } \\
\text { index } \\
\text { (ml./m. }{ }^{2} \\
\text { B.S.A.) }\end{array}$} & \multirow[t]{2}{*}{$\begin{array}{c}\text { Stroke } \\
\text { index } \\
\text { (ml./m. } .^{2} \\
\text { B.S.A.) }\end{array}$} & \multirow[t]{2}{*}{$\begin{array}{l}\text { End- } \\
\text { diastolic } \\
\text { volume } \\
\text { (ml./m.2 } \\
\text { B.S.A.) }\end{array}$} & \multirow[t]{2}{*}{$\begin{array}{c}\text { End- } \\
\text { systolic } \\
\text { volume } \\
\text { (ml./m.2 } \\
\text { B.S.A.) }\end{array}$} & \multirow[t]{2}{*}{$\frac{E S V}{E D V}$} & \multirow{2}{*}{$\begin{array}{c}\text { Right } \\
\text { ventri- } \\
\text { cular } \\
\text { stroke } \\
\text { work } \\
\text { (g.m./ } \\
\text { stroke/ } \\
\text { m.2 } \\
\text { B.S.A.) }\end{array}$} \\
\hline & & & & & & & Rest & Exercise & & & & & & \\
\hline $\begin{array}{l}\text { L.L. } \\
\text { M.C. } \\
\text { D.M. } \\
\text { E.C. } \\
\text { H.B. } \\
\text { J.L.. } \\
\text { E.M. } \\
\text { M.O. } \\
\text { E.C. } \\
\text { M.K. } \\
\text { A.F. } \\
\text { J.H. }\end{array}$ & $\begin{array}{l}28 \\
52 \\
39 \\
45 \\
31 \\
32 \\
48 \\
49 \\
41 \\
48 \\
58 \\
57\end{array}$ & $\begin{array}{l}\mathbf{F} \\
\mathbf{F} \\
\mathbf{F} \\
\mathbf{F} \\
\mathbf{F} \\
\mathbf{F} \\
\mathbf{F} \\
\mathbf{F} \\
\mathbf{F} \\
\mathbf{F} \\
\mathbf{M} \\
\mathbf{M}\end{array}$ & $\begin{array}{r}\text { I } \\
\text { III } \\
\text { II } \\
\text { II } \\
\text { I } \\
\text { II } \\
\text { II } \\
\text { I } \\
\text { III } \\
\text { III } \\
\text { I } \\
\text { II }\end{array}$ & $\begin{array}{r}78 \\
100 \\
95 \\
85 \\
76 \\
94 \\
66 \\
66 \\
74 \\
73 \\
96 \\
107\end{array}$ & $\begin{array}{c}27 \\
77-95 \\
39 \\
31 \\
31 \\
67 \\
24 \\
30 \\
62 \\
37 \\
62 \\
62\end{array}$ & $\begin{array}{l}0 \\
2 \\
2 \\
0 \\
0 \\
8 \\
4 \\
7 \\
0 \\
0 \\
0 \\
7 \\
7\end{array}$ & $\begin{array}{r}7 \\
20 \\
18 \\
11 \\
12 \\
25 \\
7 \\
11 \\
19 \\
13 \\
26 \\
5\end{array}$ & $\begin{array}{l}\frac{22}{-} \\
\overline{22} \\
\frac{32}{13} \\
13 \\
36 \\
20 \\
-\end{array}$ & $\begin{array}{l}1 \cdot 9 \\
2 \cdot 1 \\
2 \cdot 4 \\
2 \cdot 3 \\
2 \cdot 6 \\
2 \cdot 0 \\
1.9 \\
1.9 \\
2.9 \\
3 \cdot 0 \\
1.8 \\
1.6\end{array}$ & $\begin{array}{l}24 \\
21 \\
26 \\
26 \\
34 \\
22 \\
29 \\
29 \\
39 \\
41 \\
19 \\
15\end{array}$ & $\begin{array}{r}97 \\
178 \\
99 \\
110 \\
117 \\
104 \\
110 \\
112 \\
169 \\
143 \\
81 \\
48\end{array}$ & $\begin{array}{r}75 \\
156 \\
73 \\
84 \\
83 \\
82 \\
81 \\
83 \\
130 \\
102 \\
61 \\
33\end{array}$ & $\begin{array}{l}0.64 \\
1.88 \\
0.74 \\
0.76 \\
0.71 \\
0.69 \\
0.74 \\
0.64 \\
0.71 \\
0.71 \\
0.76 \\
0.69\end{array}$ & $\begin{array}{r}8 \cdot 8 \\
27 \cdot 3 \\
13.8 \\
11.0 \\
14.3 \\
20.0 \\
9.5 \\
11.8 \\
32.9 \\
20.7 \\
16.0 \\
12.7\end{array}$ \\
\hline
\end{tabular}

\section{RESULTS}

Table I summarizes the results in the first group of "normal" patients. The right ventricular systolic pressure was within normal limits $(25 \mathrm{~mm}$. $\mathrm{Hg}$ or below in this laboratory) in 5 patients and slightly raised in the one with hepatic cirrhosis. The values ranged from 17 to 30 , with a mean of $24.5 \mathrm{~mm}$. Hg. Right ventricular end-diastolic pressure was within normal limits ( $8 \mathrm{~mm}$. $\mathrm{Hg}$ or below), ranging from 3 to 7 , with a mean of $4.7 \mathrm{~mm}$. Hg. The pulmonary capillary venous pressure was normal $(12 \mathrm{~mm}$. $\mathrm{Hg}$ or below) in all, ranging from 2.5 to $10 \mathrm{~mm}$. $\mathrm{Hg}$ (mean 6.3). Cardiac index was also within normal limits, with a mean value of $2 \cdot 7$ and a range of 2.3 to $3.41 . / \mathrm{m}^{2}$ body surface area. Stroke volume varied between 32 and 85 , mean 40.5 $\mathrm{ml} . / \mathrm{m}^{2}$; end-diastolic volume between 103 and 203, mean $127.5 \mathrm{ml} . / \mathrm{m}^{2}$ : and end-systolic volume from 71 to 158 , mean $87 \mathrm{ml} . / \mathrm{m}^{2}{ }^{2}$ The ratio $\mathrm{ESV} / \mathrm{EDV}$ was 0.58 to 0.74 (mean 0.68 ).

Table II summarizes the results in the second group of patients. Right ventricular systolic pressure was raised in all, ranging from 27 to $95 \mathrm{~mm}$. Hg (mean 47-2). Right ventricular end-diastolic pressure was 0 to $8 \mathrm{~mm}$. $\mathrm{Hg}$ (mean 3.0 ). The pulmonary capillary venous pressure ranged from 5 to 26 $\mathrm{mm}$. Hg (mean 14.6) at rest and 13 to 36 (mean 22.6) on exercise. The cardiac index was 1.6 to 3.0 , with a mean of $2 \cdot 21 . / \mathrm{min} . / \mathrm{m}^{2}$, and the stroke volume 15 to $41 \mathrm{ml} . / \mathrm{m} .{ }^{2}$ (mean $27 \cdot 1$ ). The mean end-diastolic volume was 114 , with a range of 48 to $169 \mathrm{ml} . / \mathrm{m}^{2}$, and the mean end-systolic volume, 87 , with a range of 33 to $156 \mathrm{ml} . / \mathrm{m}^{2}{ }^{2} \mathrm{ESV} / \mathrm{EDV}$ ranged between 0.64 and 0.88 (mean 0.73 ). 


\section{Discussion}

The two methods currently in use to measure ventricular volumes are the indicator dilution and angiographic techniques. Unfortunately, the results obtained by the two techniques do not agree even when they are used simultaneously in the same patient (Hallermann, Rastelli, and Swan, 1963; Bartle and Sanmarco, 1966). Both methods make a series of assumptions. In the angiographic techniques the ventricle is considered to have a regular geometric shape: this approximation may be reasonably accurate when considering the left ventricle but is certainly not true of the right ventricle; the volume of dye injected to outline the ventricle also artificially increases the size of the cavity.

Reedy and Chapman (1963) have attempted to measure right ventricular volumes by measuring total heart volume and subtracting left ventricular volume and calculated septal volume from the total. This is a cumbersome method and introduces further assumptions. Thus, at present, only indicator dilution techniques are suitable for measurement of right ventricular volumes.

The main difficulties encountered with the thermodilution method are those of mixing. It has been shown that in the dog heart beating rapidly, mixing of injected indicator is complete in 85 per cent of cases four beats after maximum indicator concentration is reached (Irisawa et al., 1960). It is, therefore, reasonable to assume that at least as good a result is obtained in the human heart during the longer diastolic filling period, which is perhaps balanced by the larger volumes involved. However, the method also depends upon good mixing of atrial blood, free from indicator, diluting the indicator in the ventricle, and producing the washout curve which is subsequently analysed. If a stream of blood relatively free from indicator were picked up at the sensing site the steps produced would be too large and the ejection fraction would be overestimated. The ejection fraction as measured in this method is smaller than that found in the angiographic method. This is in favour of adequate mixing. The results found using a constant infusion technique where mixing is complete compare favourably with the present technique, and this again suggests that mixing is adequate (Shaffer, 1964). When cold saline is used as the indicator, some "cold" is lost in cooling the myocardium. The reverse effect occurs during the rewarming phase which is used to calculate the volumes. At worst a little of the myocardium will be included in the volumes measured, which will thus be slightly overestimated.

The values found in the "normal" group of patients for the ratio of end-systolic to end-diastolic volume, and for end-systolic and end-diastolic volumes are slightly higher than those found by Rapaport et al. (1965) in patients without heart disease. The values found in the second group did not differ significantly as a group from the normals $(p>0.05)$ though the highest values for ESV/EDV were found in this group. The highest value of all occurred in a patient (M.C.) who had the highest right ventricular pressure, which alternated between 77 and $95 \mathrm{~mm}$. $\mathrm{Hg}$. This alternation is suggestive of ventricular dysfunction, and this is certainly borne out by the very high ratio of ESV/EDV. Similar high ratios were found by Rapaport et al. (1965) in their group of patients in right ventricular failure. The average ratio in the "normals" here is higher than that found by this group, and as yet a normal value has not been established, but it seems that a ratio above 0.75 (ejection fraction less than $25 \%$ ) is likely to be abnormal. As stated previously, the end-systolic and end-diastolic volumes did not differ significantly between the two groups. The stroke index was, however, significantly lower in the second group (p 0.01), and this, coupled with the trend to higher ESV/EDV ratios, suggests right ventricular dysfunction. When right ventricular

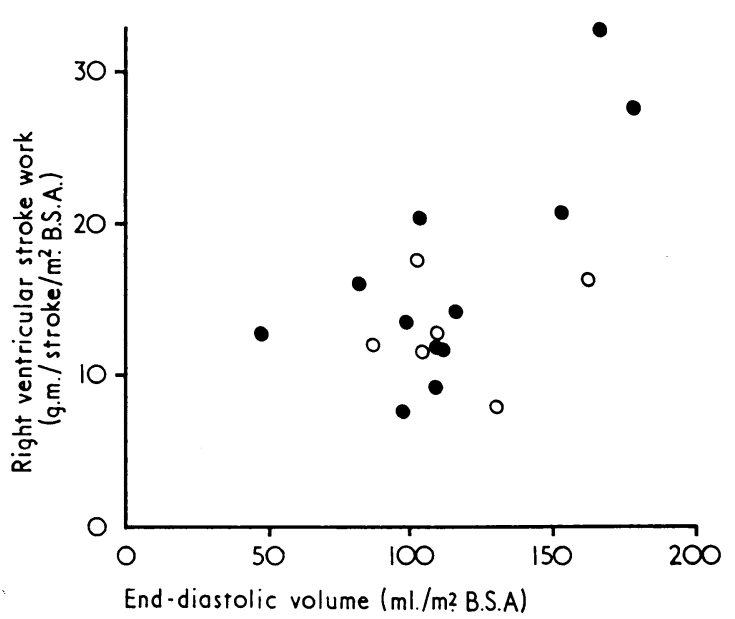

FIG. 3.-Right ventricular stroke work plotted against enddiastolic volumes. $\bigcirc$, "normals"; ๑, mitral valve disease.

work is plotted against end-diastolic volume (Fig. 3), it can be seen that there is no separation between the two groups and there seems to be a linear relation between the two parameters. The second group have uniformly higher right ventricular systolic pressures and therefore have to do more pressure work at the expense of, it seems, flow work. None of the patients here had a raised right ventricular end-diastolic pressure, though in many cases the 


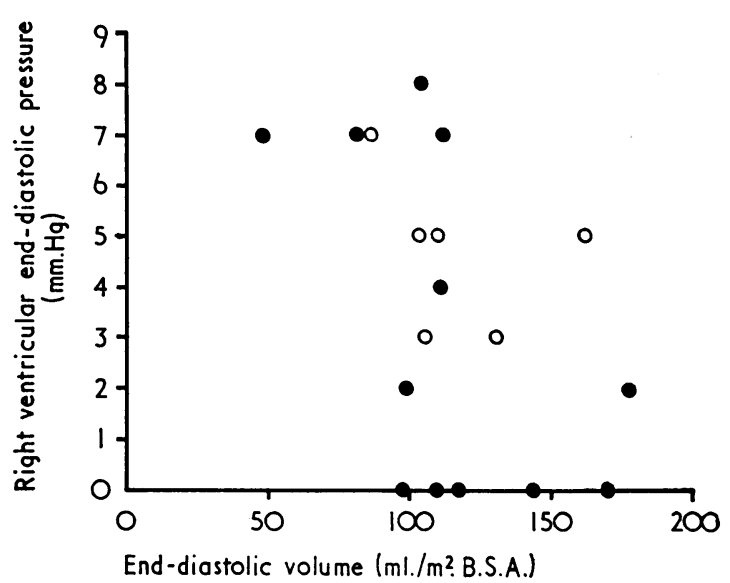

FIG. 4.-Right ventricular end-diastolic pressure plotted against end-diastolic volume. $\bigcirc$, "normals";, , mitral valve disease.

stroke index and cardiac index were low and the ejection fraction small. There was no constant relation between end-diastolic pressure and enddiastolic volume, nor between it and the ratio ESV/ EDV (Fig. 4 and 5). Therefore, changes in ventricular volumes, and particularly in the ratio ESV/EDV, seem to indicate ventricular dysfunction earlier than end-diastolic pressure or the presence of overt cardiac failure. Slight changes may be exaggerated by exercise. Rapaport et al. (1965) have shown that in subjects with normal hearts the ratio ESV/EDV decreases on exercise, whereas in patients with cardiac failure it either increases or is unchanged.

In summary, the thermodilution technique is a simple and safe method of estimating ventricular volumes. As with other techniques, certain assumptions have to be made which may introduce inaccuracies in absolute values, but comparative values in various physiological states from patient to patient should be meaningful. The ratio ESV/ EDV seems to be a good and early indicator of ventricular dysfunction. This technique is particularly of value in estimating right ventricular volumes, since these cannot be adequately measured by any other method.

\section{SUMMARY}

Right ventricular end-diastolic and end-systolic volumes have been measured in two groups of patients by the thermodilution technique. One group was thought to have "normal" hearts and the other group consisted of patients with mitral valve disease. The difficulties of the method are

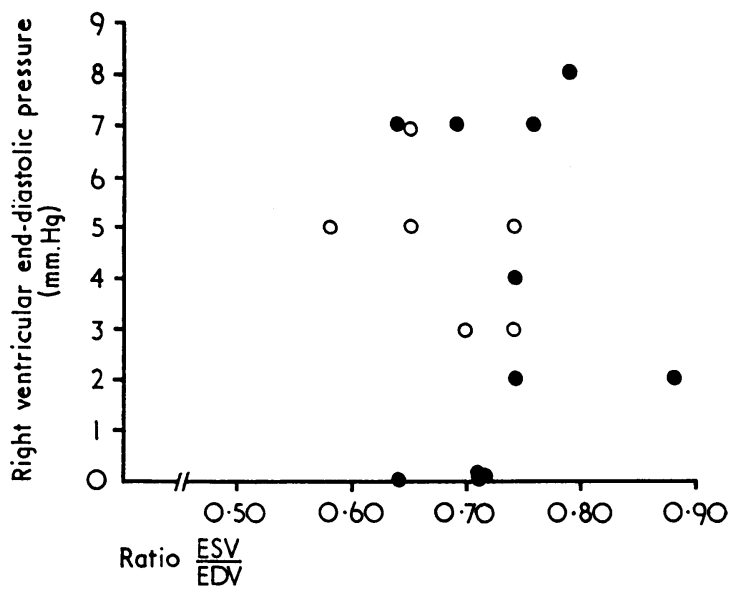

FIG. 5.-Right ventricular end-diastolic pressure plotted against the ratio $\frac{\mathrm{ESV}}{\mathrm{EDV}}$. $\bigcirc$, "normals"; $\bullet$, mitral valve disease.

discussed. The highest values for the ratio ESV/ EDV and also end-diastolic and end-systolic volumes were found in patients with mitral valve disease. It is suggested that a high ratio ESV/EDV is a better measure of ventricular function than a raised end-diastolic pressure.

The authors would like to thank Mr. D. Kitchen for making the thermistor catheters; and the British Heart Foundation for financial support.

\section{REFERENCES}

Arvidsson, H. (1961). Angiographic determination of left ventricular volume. Acta. radiol. (Stockh.), 56, 321.

Bartle, S. H., and Sanmarco, M. E. (1966). Measurement of left ventricular volume by biplane angiocardiography and indicator-washout techniques: a comparison in the canine heart. Circulat. Res., 19, 295.

Bing, R. J., Heimbecker, R., and Falholt, W. (1951). An estimation of the residual volume of blood in the right ventricle of normal and diseased human hearts in vivo. Amer. Heart $\mathcal{F} ., 42,483$.

Brecher, G. A., and Hubay, C. A. (1955). Pulmonary blood flow and venous return during spontaneous respiration. Circulat. Res., 3, 210.

Bristow, J. D., Farrehi, C., Lewis, R. P., and Griswold, H. E. (1964). Left ventricular volume studies in man by thermodilution. Clin. Res., 12, 76.

Dodge, H. T., Sandler, H., Ballew, D. W., and Lord, J. D. (1960). The use of biplane angiocardiography for the measurement of left ventricular volume in man. Amer. Heart F., 60, 762.

Elliott, W. C., Lane, F. J., and Gorlin, R. (1964). Measurement of left ventricular volume in man by thermodilution. Amer. F. Cardiol., 13, 106.

Geigel, R. (1920). Lehrbuch der Herzkrankheiten. Bergmann, Munich. 
Hallermann, F. J., Rastelli, G. C., and Swan, H. J. C. (1963). Comparison of left ventricular volumes by dye dilution and angiographic methods in the dog. Amer. $\mathcal{F}$. Physiol., 204, 446.

Holt, J. P. (1956). Estimation of the residual volume of the ventricle of the dog's heart by two indicator dilution techniques. Circulat. Res., 4, 187.

Irisawa, H., Wilson, M. F., and Rushmer, R. F. (1960). Left ventricle as a mixing chamber. Circulat. Res., 8, 183.

Kahlstorf, A. (1932). Über eine orthodiagraphische Herzvolumenbestimmung. Fortschr. Röntgenstr., 45, 123.

Lewis, R. P., Bristow, J. D., and Griswold, H. E. (1967). Peripheral arterial dilution curves in the appraisal of left ventricular diastolic volume. Amer. Heart f., 73, 165.

Miller, G. A. H., and Swan, H. J. C. (1964). Effect of chronic pressure and volume overload on left heart volumes in subjects with congenital heart disease. Circulation, 30, 205.

Rapaport, E., Wiegand, B. D., and Bristow, J. D. (1962). Estimation of left ventricular residual volume in the dog by a thermodilution method. Circulat. Res., 11, 803.
Wong, M., Ferguson, R. E., Bernstein, P., and Weigand, B. D. (1965). Right ventricular volumes in patients with and without heart failure. Circulation, 31, 531.

Reedy, T., and Chapman, C. B. (1963). Measurement of right ventricular volume by cineangiofluorography. Amer. Heart f., 66, 221.

Rohrer, F. (1916). Volumenbestimmung von Körperhöhlen und Organen auf orthodiagraphischen Wege. Fortschr. Röntgenstr., 24, 285.

Rolett, E. L., Sherman, H., and Gorlin, R. (1964). Measurement of left ventricular volume by thermodilution: an appraisal of technical errors. F. appl. Physiol., 19, 1164.

Rushmer, R. F., and Thal, N. (1951). The mechanics of ventricular contraction. A cinefluorographic study. Circulation, 4, 219.

Shaffer, A. B. (1964). Estimation of ventricular volumes by a constant infusion indicator dilution technique. Circulat. Res., 15, 168.

Starling, E. H., and Visscher, M. B. (1927). The regulation of the energy output of the heart. $\mathcal{F}$. Physiol. (Lond.), 62, 243. 